\title{
Skala Pengukuran Karakter Adil: Salah Satu Instrumen sebagai Piranti BADRANAYA (Board-game Karakter Konselor Multibudaya)
}

\author{
Nora Yuniar Setyaputri' ${ }^{1}$, Yuanita Dwi Krisphianti'2 ${ }^{2}$, Rosalia Dewi Nawantara ${ }^{3}$ \\ setyaputrinora@gmail.com¹, Ju.wahyu@gmail.com², Rosaliadewi11@gmail.com³ \\ Program Studi Bimbingan dan Konseling, Universitas Nusantara PGRI Kediri $1,2,3$
}

\begin{abstract}
It is very important for multicultural counselor to have fairness character. At school, there is an issue of less professionalism counselors because of less fairness character. The results of preliminary study conducted at undergraduate's students of Guidance and Counseling Department at University of Nusantara PGRI Kediri prove that the students as candidate of counselor still discriminate the personality of counselee, less neutral when counselee tells the problem, and give labeling on counselee. Therefore, it is important to do special interventions to improve their fairness character become competent multicultural counselors. To Intervent the candidate of counselors can use certain media such as BADRANAYA (Multi-Cultural Character Board-game Counselor). The aim of this research is to develop BADRANAYA which can be accepted theoritically and practically. The research method used is research and development (Borg \& Gall 1983). At present, the research process is in the third procedure namely the Development of Initial Product Draft, one of them is preparation of instruments. The validity and reliability are very important to obtain valid data regarding the level of fairness character for candidate of multicultural counselors. This article is limited to the validity and reliability of the Fairness Character Measurement Scale. Based on the results of the validity which is tested to 32 undergraduate students at University of Nusantara PGRI Kediri obtained 12 valid items with a reliability index of 0.834 . The 12 items also have a very high reliability index that is represented each indicator of fairness character. While the results of the validation of the instrument, the fairness character measurement scale can be used as a measurement of the fairness character of candidate multicultural counselors in the next research procedure.
\end{abstract}

Keywords: justice character measurement scale, justice character, badranaya

\begin{abstract}
Abstrak
Karakter adil sangat penting dimiliki oleh seorang konselor multibudaya. Isu kurangnya profesionalitas Konselor di lapangan dapat terjadi berawal dari kurang dimilikinya karakter adil ini. Hasil studi pendahuluan yang dilakukan pada mahasiswa S1 BK UNP Kediri membuktikan bahwa calon konselor tersebut masih melakukan perilaku membeda-bedakan kepribadian konseli, kurang netral ketika konseli menceritakan masalahnya, dan munculnya pelabelan pada konseli. Maka, perlu dilakukan intervensi khusus untuk meningkatkan karakter adil ini agar mereka dapat menjadi Konselor Multibudaya yang kompeten. Intervensi yang dilakukan pada calon konselor tersebut dapat menggunakan media tertentu seperti BADRANAYA (Board-game Karakter Konselor Multibudaya). Penelitian ini bertujuan untuk mengembangkan BADRANAYA yang dapat diterima secara teoeretis dan praktis. Metode penelitian yang digunakan adalah reseach and development (Borg \& Gall 1983). Saat ini tahap penelitian memasuki tahap ketiga yaitu Pengembangan Draft Awal Produk dimana salah satunya adalah penyusunan instrumen. Validitas dan reliabitas instrumen sangat penting diperhatikan untuk mendapatkan data yang sahih mengenai tingkat karakter adil calon konselor multibudaya. Pada artikel ini dibatasi sampai pada diperolehnya hasil validitas dan reliabilitas Skala Pengukuran Karakter Adil. Berdasarkan hasil validitas instrumen yang diujikan kepada 32 mahasiswa S1 BK Universitas Nusantara PGRI Kediri, diperoleh 12 aitem valid dengan indeks reliabilitas sebesar 0,834. Ke-12 aitem yang juga memiliki indeks reliabilitas sangat tinggi tersebut telah mewakili setiap indikator karakter adil. Berdasarkan hasil validasi instrumen tersebut, maka Skala Pengukuran Karakter Adil dapat digunakan sebagai alat ukur karakter adil calon konselor multibudaya pada tahap penelitian selanjutnya.
\end{abstract}

Kata Kunci: skala pengukuran karakter adil, karakter adil, badranaya. 


\section{PENDAHULUAN}

Konselor multibudaya yang efektif harus memiliki kompetensi konselor multibudaya yang baik. Agar menjadi konselor multibudaya yang baik, kompetensi multibudaya harus dibiasakan dan dilatihkan karena kompetensi ini bukan hal yang dapat muncul secara tiba-tiba (Corey, 2013). Selain menjadi diri konselor multibudaya yang efektif, pelaksanaan konseling yang efektif juga perlu diperhatikan. Salah satu indikator agar konseling berjalan efektif menurut Corey $(2009 ; 2013)$ harus memperhatikan pengaruh unsur budaya yang ada pada konseli maupun konselor. Hal ini dapat diartikan bahwa pelaksanaan konseling yang efketif adalah ketika dalam proses konseling multibdaya seorang konselor dapat memahami keadaan budaya konselor itu sendiri, keadaan budaya konselinya dan keadaan lingkungan mereka. Constantine \& Sue (2005) menguatkan bahwa pemahaman yang baik dan pengakuan adanya budaya yang berbeda ini dapat dilakukan sebagai wujud upaya peningkatan kualitas diri konselor baik dari segi pendidikan, pelatihan, praktik bahkan penelitian. Sue, Arredondo \& McDavis (1992) mengemukakan ada 3 kompetensi multibudaya konselor adalah kepercayaan dan sikap, pengetahuan, serta keterampilan. Dapat disimpulkan bahwa dapat memahami keadaan budaya serta memiliki karakter diri yang dapat mendukung hal tersebut merupakan salah satu cara agar dapat menjadi konselor multibudaya yang efektif.

Karakter ideal konselor multibudaya tersebut dapat dikaitkan dengan nilai luhur Semar. Semar dipilih sebagai model karena mempunyai keunikan-keunikan tertentu yang tidak dimiliki oleh tokoh wayang lainnya. Semar adalah salah satu sosok yang fenomenal dalam dunia perwayangan dan cukup dikenal oleh masayarakat Indonesia khususnya di Pulau Jawa. Terdapat beberapa sebutan Semar dimana salah satunya adalah Badranaya (Notopertomo \& Jatirahayu, 2012). Badranaya dapat dimaknai dengan seseorang yang memiliki sifat membangun dan selalu melaksanakan perintah Tuhan demi kesejahteraan orang lain (Hermawan, 2013). Di samping wujudnya yang tergolong unik, Semar merupakan tokok pewayangan yang memiliki sifat luhur. Menurut Setyaputri (2015) keunikan dari Semar merupakan keunikan yang dibuat oleh manusia dan untuk manusia juga. Keunikan ini bermuatan nilai-nilai kebijaksanaan dalam versi manusia. Dengan ini muatan nilai dalam diri Semar dapat memasuki berbagai lapisan kehidupan sosial. Tentunya hal ini berkaitan dengan sistem sosial budaya dalam kehidupan bermasyarakan termasuk pada kehidupan sosial budaya konselor maupun konseli. Dengan arti bahwa sistem sosial budaya tersebut mempengaruhi karakter seseorang yang ada di dalamnya termasuk konselor multibudaya.

Setyaputri (2017) telah merumuskan 12 karakter ideal konselor multibudaya berdasarkan nilai luhur Semar. Salah satu dari keduabelas karakter tersebut adalah karakter adil. Karakter adil berkaitan dengan keseimbangan ketika proses pemberian pelayanan BK oleh konselor terhadap konseli. Indikator karakter adail ini ada 3 yaitu tidak membeda-membedakan, netral dan tidak melabeli dalam konteks negatif. Isu-isu mengenai kurangnya profesionalitas Konselor di lapangan berawal dari karakter konselor tersebut khususnya karakter adil. Berdasarkan hasil studi pendahuluan yang dilakukan pada mahasiswa S1 BK Universitas Nusantara PGRI Kediri diketahui bahwa calon konselor tersebut masih sering melakukan perilaku membeda-bedakan kepribadian konseli satu dengan yang lain, kurang netral ketika konseli menceritakan masalahnya, dan munculnya pelabelan (stereotype) 
pada konseli mereka. Oleh karena itu, perlu dilakukan intervensi khusus untuk meningkatkan karakter adil ini agar mereka dapat menjadi Konselor Multibudaya yang kompeten di bidangnya. Intervensi yang dilakukan pada para calon konselor tersebut dapat menggunakan salah satu jenis media tertentu.

Penggunaan media dalam proses intervensi atau pemberian layanan BK tersebut sangat penting karena media merupakan salah satu komponen penting dalam sistem BK (Nursalim, 2013). Maka, peran media sangat diperlukan untuk menunjang keefektifan layanan BK agar tujuan yang diharapkan dapat tercapai. Media yang dipilih adalah board game. Menurut Setyanugrah \& Setyadi (2017) board game merupakan salah jenis media visual. Prameswara \& Siswanto (2016) menambahkan bahwa board game ini dapat dikemas dalam bentuk permainan. Pendapat ini didukung oleh Yunita dan Wirawan (2017) yang menyatakan bahwa board game adalah jenis permainan dimana alat-alat atau bagian-bagian ditempatkan, dipindahkan, atau digerakkan pada permukaan yang telah ditandai atau dibagi-bagi menurut seperangkat aturan. Board game ini dikembangkan untuk menumbuhkan karakter ideal konselor multibudaya pada mahasiswa S1 BK UN PGRI Kediri. Nama yang diberikan pada media board game tersebut adalah BADRANAYA.

BADRANAYA merupakan akronim dari Board-game Karakter Konselor Multibudaya. BADRANAYA dikembangkan dalam bentuk papan permainan dimana dalam permainan tersebut terdapat materi yang akan menjadi bahan diskusi dalam proses bimbingan. BADRANAYA ini dirancang sebagai perjalanan/ perkelanaan seorang Kesatria dalam mencari "harta karun Semar". Harta karun tersebut berada pada ujung perjalanan/ perkelanaan tersebut. Yang dimaksud "harta karun Semar" itu sendiri sebenarnya adalah sosok utuh Konselor yang memiliki karakter justice (adil). Untuk mendapatkan itu, pemain yang diibaratkan seorang Kesatria tersebut harus melalui perjalanan dimana di dalam perjalanan tersebut terdapat materi-materi yang berkaitan dengan karakater justice (adil). Dimana dalam pempelajari materi tersebut, pemain harus menyelesaikan tugas-tugas yang temanya disesuaikan dengan materi. Kriteria pengembangan media yang digunakan mengacu pada kriteria pengembangan media BK yang dikemukakan oleh Nursalim (2013). Dengan terpenuhinya kriteria-kriteria pengembangan media tersebut dimaksudkan agar tujuan penelitian ini dapat terpernuhi yaitu BADRANAYA dapat diterima secara teoretis dan praktis sebagai media BK. Di dalam proses penelitian dan pengembangan BADRANAYA ini satu hal yang tidak kalah penting adalah kesahihan dari alat ukur itu sendiri. Dimana instrumen yang digunakan dapat mengukur apa yang akan diukur serta terbukti keajegannya. Maka, karakter adil yang hendak ditingkatkan dengan media BADRANAYA ini terlebih dahulu harus dapat diketahui seberapa tinggi ataupun rendah tingkatannya dengan menggunakan alat ukur berupa Skala Pengukuran Karakter Adil. Proses penyusunan skala ini berdasarkan indikator dari karakter adil yang telah dikemukakan oleh Setyaputri (2017).

\section{METODE PENELITIAN}

Metode penelitian yang digunakan adalah research and development, dimana tahapannya mengacu pada langkah-langkah penelitian dan pengembangan Borg \& Gall (1983). Pada penelitian ini kesepuluh langkah penelitian dan pengembangan Borg \& Gall (1983) tersebut tidak dilaksanakan secara 
Efektor, Volume 7 Issue 1, 2020, Pages 90 - 97

Nora Yuniar Setyaputri, Yuanita Dwi Krisphianti, Rosalia Dewi Nawantara

keseluruhan. Kesepuluh langkah tersebut akan dimodifikasi disesuaikan dengan kebutuhan penelitian serta bidang fokus pada penelitian ini. Adapun prosedur pengembangan produk pada penelitian ini sebagai berikut.

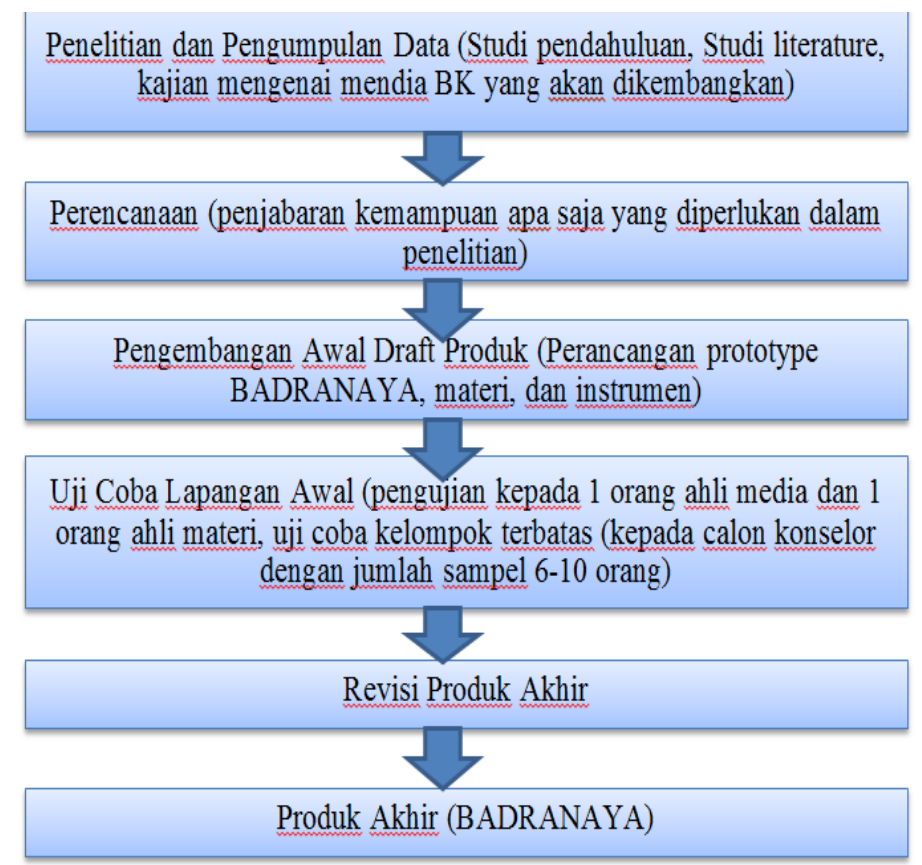

Gambar 1. Prosedur Pengembangan BADRANAYA

Populasi penelitian adalah seluruh mahasiswa S1 BK UNP Kediri sebanyak 431 mahasiswa per tahun ajaran 2019/2020. Sedangkan sampel ditentukan dengan purposive sampling dimana yang menjadi sampel penelitian adalah mahasiswa S1 BK UNP Kediri yang mempunyai karakter adil yang memasuki rentang sangat rendah maupun rendah. Teknik pengumpulan data yang digunakan dalam penelitian ini adalah kuesioner dan skala psikologis. Kuesioner dan skala psikologis adalah teknik pengumpulan data sedangkan untuk praktisnya teknik ini ditransformasikan dalam bentuk atau format instrumen yang berupa kuesioner penilaian ahli dan skala pengukuran karakter adil konselor multibudaya. Saat ini tahap penelitian memasuki tahap ketiga yaitu Pengembangan Draft Awal Produk dimana salah satunya adalah penyusunan instrumen berupa Skala Pengukuran Karakter Adil. Penyusunan skala ini berdasarkan indikator karakter adil yaitu tidak membeda-membedakan, netral dan tidak melabeli dalam konteks negatif. Setelah kisi-kisi instrumen di susun, terdapat 20 item yang dijabarkan dari masingmasing indikator tersebut. Subjek validasi instrumen adalah 32 mahasiswa S1 BK UNP Kediri. Validitas instumen menggunakan korelasi product moment pearson dan relibailitas instrumen menggunakan alpha cronbach dengan bantuan SPSS 20.0 for windows.

\section{HASIL DAN PEMBAHASAN}

Berdasarkan penyusunan kirsi-kisi instrumen diperoleh 20 item yang dijabarkan dari setiap indikator karakter adil. Adapun kisi-kisi instrument dapat dilihat pada tabel 1 berikut. 
Efektor, Volume 7 Issue 1, 2020, Pages 90 - 97

Nora Yuniar Setyaputri, Yuanita Dwi Krisphianti, Rosalia Dewi Nawantara

Tabel 1. Kisi-Kisi Skala Pengukuran Karakter Adil

\begin{tabular}{|c|c|c|c|c|c|}
\hline NO. & VARIABEL & INDIKATOR & DESKRIPTOR & PERNYATAAN & ITEM \\
\hline \multirow[t]{20}{*}{1.} & \multirow[t]{20}{*}{ Karakter Adil } & \multirow{7}{*}{$\begin{array}{l}\text { Tidak } \\
\text { Membeda- } \\
\text { bedakan }\end{array}$} & \multirow[t]{7}{*}{$\begin{array}{l}\text { Tidak menjadikan } \\
\text { individu berlainan }\end{array}$} & $\begin{array}{l}\text { Saya tidak melayani konseli yang } \\
\text { berstatus sosial rendah. (-) }\end{array}$ & 1 \\
\hline & & & & $\begin{array}{l}\text { Saya tidak memberikan layanan BK } \\
\text { pada konseli yang segama dengan } \\
\text { saya saja. }(+)\end{array}$ & 4 \\
\hline & & & & $\begin{array}{l}\text { Saya bersedia membantu orang lain } \\
\text { yang berbeda ras dengan saya. }(+)\end{array}$ & 7 \\
\hline & & & & $\begin{array}{l}\text { Saya menerima orang lain dengan } \\
\text { syarat tertentu. }(-)\end{array}$ & 10 \\
\hline & & & & $\begin{array}{l}\text { Saya menganggap orang lain } \\
\text { sederajat. }(+)\end{array}$ & 13 \\
\hline & & & & $\begin{array}{l}\text { Saya paling senang memberikan } \\
\text { layana pada konseli yang aktif saja. (-) }\end{array}$ & 16 \\
\hline & & & & $\begin{array}{l}\text { Saya memberikan layanan konseling } \\
\text { pada siswa yang penurut saja. (-) }\end{array}$ & 19 \\
\hline & & \multirow[t]{6}{*}{ Netral } & \multirow[t]{6}{*}{$\begin{array}{lr}\text { Tidak berpihak } \\
\text { pada ratu } \\
\text { kelompok tertentu }\end{array}$} & $\begin{array}{l}\text { Saya lebih menyukai untuk mencari } \\
\text { jalan tengah ketika berdiskusi dengan } \\
\text { orang lain. }(+)\end{array}$ & 2 \\
\hline & & & & $\begin{array}{l}\text { Saya tidak mengarahkan konseli untuk } \\
\text { mempunyai pola pikir yang sama } \\
\text { dengan saya. }(+)\end{array}$ & 5 \\
\hline & & & & $\begin{array}{l}\text { Saya tidak nyaman jika berada di luar } \\
\text { kelompok saya. (-) }\end{array}$ & 8 \\
\hline & & & & $\begin{array}{l}\text { Saya sulit bergaul dengan jenis } \\
\text { kelompok tertentu. (-) }\end{array}$ & 11 \\
\hline & & & & $\begin{array}{l}\text { Saya berpihak pada orang-orang yang } \\
\text { menguntungkan saya. (-) }\end{array}$ & 14 \\
\hline & & & & $\begin{array}{l}\text { Saya mendengarkan dengan seksama } \\
\text { pendapat orang lain yang berbeda } \\
\text { pendapat. }(+)\end{array}$ & 17 \\
\hline & & \multirow[t]{7}{*}{ Tidak Melabeli } & \multirow{7}{*}{$\begin{array}{ll}\text { Tidak } & \\
\text { memberikan } \\
\text { konsepsi atau } \\
\text { prasangka } \\
\text { subjektif } \\
\text { tidak tepat } & \\
\end{array}$} & $\begin{array}{l}\text { Saya memberikan prediksi nakal bagi } \\
\text { anak yang selalu melanggar aturan. (-) }\end{array}$ & 3 \\
\hline & & & & $\begin{array}{l}\text { Saya tidak menganggap orang lain } \\
\text { yang mempunyai tato di badannya itu } \\
\text { buruk. }(+)\end{array}$ & 6 \\
\hline & & & & $\begin{array}{l}\text { Saya sering menyebut orang lain yang } \\
\text { tidak cekatan dengan sebutan "LOLA". } \\
(-)\end{array}$ & 9 \\
\hline & & & & $\begin{array}{l}\text { Saya memiliki prasangka positif } \\
\text { terhadap orang lain. }(+)\end{array}$ & 12 \\
\hline & & & & $\begin{array}{l}\text { Saya senang memberikan predikat } \\
\text { pada orang lain sesuai dengan } \\
\text { performance mereka. (-) }\end{array}$ & 15 \\
\hline & & & & $\begin{array}{l}\text { Saya menerima konseli yang datang ke } \\
\text { ruang BK meski dia tidak } \\
\text { menggunakan atribut sekolah lengkap. } \\
(+)\end{array}$ & 18 \\
\hline & & & & $\begin{array}{l}\text { Saya menilai konseli dari caranya } \\
\text { berpakaian. (-) }\end{array}$ & 20 \\
\hline
\end{tabular}

Setelah kisi-kisi selesai instrumen ini disebarkan kepada 32 mahasiswa S1 BK UNP Kediri dan setelah data diperoleh dilakukan uji validitas instrumen menggunakan korelasi product moment pearson. Diketahui dari hasil uji validitas instrument diperoleh 12 aitem valid dan 8 item tidak valid. Adapun data validitas instrumen dapat dilihat pada tabel 2 berikut. 
Efektor, Volume 7 Issue 1, 2020, Pages 90 - 97

Nora Yuniar Setyaputri, Yuanita Dwi Krisphianti, Rosalia Dewi Nawantara

Tabel 2. Hasil Validitas Skala Pengukurankarakter Adil

\begin{tabular}{cccc}
\hline ITEM & $\begin{array}{c}\text { SKOR KORELASI PRODUCT } \\
\text { MOMENT PEARSON/ } \mathbf{r} \text { hitung }\end{array}$ & $\begin{array}{c}\mathbf{r} \text { tabel } \mathbf{N}=\mathbf{3 2} \text { dengan taraf } \\
\text { sigifikansi } \mathbf{5} \%\end{array}$ & KESIMPULAN \\
\hline 1 & 0.620 & 0.349 & VALID \\
\hline 2 & 0.25 & 0.349 & TIDAK VALID \\
\hline 3 & 0.410 & 0.349 & VALID \\
\hline 4 & 0.430 & 0.349 & VALID \\
\hline 5 & 0.697 & 0.349 & VALID \\
\hline 6 & 0.101 & 0.349 & TIDAK VALID \\
\hline 7 & 0.183 & 0.349 & TIDAK VALID \\
\hline 8 & 0.271 & 0.349 & TIDAK VALID \\
\hline 9 & 0.34 & 0.349 & TIDAK VALID \\
\hline 10 & 0.759 & 0.349 & VALID \\
\hline 11 & 0.556 & 0.349 & VALID \\
\hline 12 & 0.331 & 0.349 & TIDAK VALID \\
\hline 13 & 0.612 & 0.349 & VALID \\
\hline 14 & 0.533 & 0.349 & VALID \\
\hline 15 & 0.444 & 0.349 & VALID \\
\hline 16 & 0.333 & 0.349 & TIDAK VALID \\
\hline 17 & 0.602 & 0.349 & VALID \\
\hline 18 & 0.732 & 0.349 & VALID \\
\hline 19 & 0.579 & 0.349 & VALID \\
\hline 20 & 0.183 & 0.349 & TIDAK VALID \\
\hline
\end{tabular}

Setelah diketahui item yang valid dan tidak valid maka disusun kembali kisi-kisi Skala Pengukuran Karakter Adil untuk memastikan bahwa masing-masing indikator terwakili. Adapun kisi-kisi instrument setelah validitas dapat dilihat pada tabel 3 .

Tabel 3. Kisi-Kisi Skala Pengukuran Karakter Adil Setelah Uji Validitas

\begin{tabular}{|c|c|c|c|c|c|}
\hline NO. & VARIABEL & INDIKATOR & DESKRIPTOR & PERNYATAAN & ITEM \\
\hline \multirow[t]{12}{*}{1.} & \multirow[t]{12}{*}{$\begin{array}{l}\text { Karakter } \\
\text { Adil }\end{array}$} & \multirow{5}{*}{$\begin{array}{l}\text { Tidak } \\
\text { Membeda- } \\
\text { bedakan }\end{array}$} & \multirow[t]{5}{*}{$\begin{array}{l}\text { Tidak menjadikan } \\
\text { individu berlainan }\end{array}$} & $\begin{array}{l}\text { Saya tidak melayani konseli yang berstatus sosial } \\
\text { rendah. (-) }\end{array}$ & 1 \\
\hline & & & & $\begin{array}{l}\text { Saya tidak memberikan layanan BK pada konseli } \\
\text { yang segama dengan saya saja. }(+)\end{array}$ & 4 \\
\hline & & & & Saya menerima orang lain dengan syarat tertentu. $(-)$ & 7 \\
\hline & & & & Saya menganggap orang lain sederajat. $(+)$ & 10 \\
\hline & & & & $\begin{array}{l}\text { Saya memberikan layanan konseling pada siswa } \\
\text { yang penurut saja. (-) }\end{array}$ & 12 \\
\hline & & \multirow[t]{4}{*}{ Netral } & \multirow{4}{*}{$\begin{array}{lr}\text { Tidak } & \text { berpihak } \\
\text { pada } & \text { satu } \\
\text { kelompok tertentu }\end{array}$} & $\begin{array}{l}\text { Saya tidak mengarahkan konseli untuk mempunyai } \\
\text { pola pikir yang sama dengan saya. }(+)\end{array}$ & 2 \\
\hline & & & & Saya sulit bergaul dengan jenis kelompok tertentu. (-) & 5 \\
\hline & & & & $\begin{array}{l}\text { Saya berpihak pada orang-orang yang } \\
\text { menguntungkan saya. }(-)\end{array}$ & 8 \\
\hline & & & & $\begin{array}{l}\text { Saya mendengarkan dengan seksama pendapat } \\
\text { orang lain yang berbeda pendapat. }(+)\end{array}$ & 11 \\
\hline & & \multirow[t]{3}{*}{$\begin{array}{l}\text { Tidak } \\
\text { Melabeli }\end{array}$} & \multirow{3}{*}{ 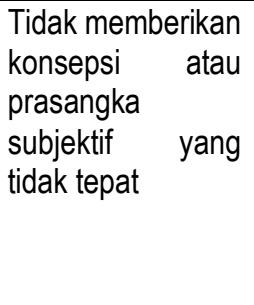 } & $\begin{array}{l}\text { Saya memberikan prediksi nakal bagi anak yang } \\
\text { selalu melanggar aturan. (-) }\end{array}$ & 3 \\
\hline & & & & $\begin{array}{l}\text { Saya senang memberikan predikat pada orang lain } \\
\text { sesuai dengan performance mereka. }(-)\end{array}$ & 6 \\
\hline & & & & $\begin{array}{l}\text { Saya menerima konseli yang datang ke ruang BK } \\
\text { meski dia tidak menggunakan atribut sekolah } \\
\text { lengkap. }(+)\end{array}$ & 9 \\
\hline
\end{tabular}


Dari penyusunan ulang kisi-kisi instrumen pada tabel 3 diketahui bahwa masing-masing indikator karakter adil telah terwakili. Maka, untuk memastikan keajegan dari skala ini dilakukan uji reliabilitas menggunakan alpha cronbach dengan bantuan SPSS 20.0 for windows. Adapun hasil uji reliabilitas dapat dilihat pada tabel 4 berikut.

Tabel 4. Hasil Uji Reliabilitas

\begin{tabular}{ll}
\hline Reliability Statistics & \\
\hline Cronbach's Alpha & N of Items \\
\hline 0.834 & 12 \\
\hline
\end{tabular}

Berdasarkan hasil uji reliabilitas instrumen diperoleh skor alpha cronbach sebesar 0.834 . Dari besaran ini dapat disimpulkan bahwa keajegan dari skala ini tergolong tinggi dan tentunya dapat dipakai untuk pengambilan keputusan mengenai tingkat karakter adil calon konselor multibudaya. Pendapat ini merujuk pada pendapat GrothMarnat (2009) yang mengatakan bahwa koefisien reliabilitas sebesar 0,70 atau lebih pada umumnya dianggap adekuat untuk maksud-maksud penelitian. Oleh karena itu, instrumen berupa Skala Pengukuran Karakter Adil ini dapat digunakan sebagai alat ukur karakter adil pada tahap penelitian selanjutnya guna mendapatkan subjek penelitian yang benar-benar sesuai dengan kriteria pemilihan subjek penelitian.

Uji validitas dan reliabilitas dalam sebuah penelitian penting untuk dilaksanakan, hal ini diperkuat dengan pendapat dari Arifin (2017) yang mengatakan bahwa validitas, reliabilitas, tingkat kesukaran, daya pembeda dan pengecoh (distraktor) merupakan hal yang penting yang harus diperhatikan oleh peneliti agar instrumen yang dibuat menjadi baik, sehingga bisa digunakan dalam menghasilkan data yang baik pula. Selain itu, pendapat lain juga mengatakan bahwa instrumen penelitian merupakan alat yang digunakan untuk mengukur data objek dari variabel penelitian, kualitas dari sebuah instrumen dipengaruhi oleh pengukuran subjek, pengguna instrumen dan instrumen itu sendiri, sehingga uji validitas dan reliabilitas harus dilakukan sebelum instrumen itu digunakan (Yusup, 2018). Berdasarkan hasil dari penelitian dan pendapat di atas maka dapat disimpulkan bahwa uji validitas dan reliabilitas yang dilakukan pada skala pengukuran Karakter Adil adalah suatu tindakan yang tepat dalam tahap penelitian ini, karena kualitas dari skala pengukuran ini salah satunya tergantung dari hasil uji validitas dan reliabilitas instrumen.

\section{SIMPULAN}

Berdasarkan pemaparan di atas dapat diketahui bahwa pengembangan media BK bernama BADRANAYA ini menggunakan tahapan penelitian dan pengembangan Borg \& Gall 1983 yang dimodifikasi sesuai kebutuhan penelitian menjadi 6 langkah Dimana tahap penelitian saat ini memasuki tahap ketiga yaitu Pengembangan Draft Awal Produk dimana salah satunya adalah penyusunan instrumen berupa Skala Pengukuran Karakter Adil. Validitas dan reliabitas instrumen berupa Skala Pengukuran Karakter Adil sangat penting diperhatikan untuk mendapatkan data yang sahih mengenai tingkat karakter adil calon konselor multibudaya. Tahap ini perlu diperhatikan guna untuk memenuhi ketercapaian tujuan penelitian. Berdasarkan hasil validitas instrumen yang diujikan kepada 32 mahasiswa S1 BK Universitas Nusantara PGRI Kediri, diperoleh 12 item valid dengan indeks reliabilitas sebesar 0,834. Ke-12 item yang juga memiliki indeks reliabilitas sangat tinggi tersebut telah mewakili 
Efektor, Volume 7 Issue 1, 2020, Pages 90 - 97

Nora Yuniar Setyaputri, Yuanita Dwi Krisphianti, Rosalia Dewi Nawantara

setiap indikator karakter adil. Berdasarkan hasil validasi instrumen tersebut, maka Skala Pengukuran Karakter Adil dapat digunakan sebagai alat ukur karakter adil calon konselor multibudaya pada tahap penelitian selanjutnya.

\section{DAFTAR RUJUKAN}

Arifin, Z. 2017. Kriteria Instrumen dalam Suatu Penelitian. Jurnal Theorems (The Original Research of Mathematics), Vol2, No 1. (Online). jurnal.unma.ac.id/index.php/th/article/view/571

Borg, W.R. \& Gall, M.D. 1983. Educational Research. An Introduction. White Plain, New York: Longman, Inc.

Constantine, M.G., \& Sue, D.W. 2005. Strategies for Building Multicultural Competence in Mental Health and Educational Settings. Canada: John Wiley \& Sons, Inc.

Corey, G. 2009. Theory and Practice of Counseling \& Psychotherapy, Eight Edition. Belmot, CA: Brooks/Cole.

Corey, G. 2013. Theory and Practice of Counseling \& Psychotherapy, Ninth Edition. Belmot, CA: Brooks/Cole.

Groth-Marnat, G. 2009. Handbook of Psychological Assesment. Terjemahan Helly Prajitno Soetjipto \& Sri Mulyantini Soetjipto. 2010. Yogyakarta: Pustaka Pelajar.

Hermawan, D. 2013. Semar \& Kentut Kesayangannya. Jogjakarta: DIVA Press.

Notopertomo, M., \& Jatirahayu, W. 2012. 51 Karakter Tokoh Wayang Populer. Klaten: PT Hafamira.

Nursalim, M. 2013. Pengembangan Media Bimbingan dan Konseling. Jakarta: PT Indeks.

Prameswara, A., \& Siswanto, R. 2016. Perancangan Board Game Edukasi sebagai Media Pembelajaran untuk Menumbuhkan Minat Baca Anak Jalanan di Bekasi. E-Proceeding of Art \& Design, Vol 3(3): 423-430.

Setyanugrah, F., \& Setyadi, D.I. 2017. Perancangan Board Game sebagai Media Pembelajaran Mitigasi Kebakaran untuk Anak Sekolah Dasar Usia 8-12 di Surabaya. Jurnal Sains dan Seni ITS, Vol 6(1): 62-68.

Setyaputri, N.Y. 2015. Koneksitas Nilai-nilai Luhur di dalam Semar (Badranaya) terhadap Ciri-ciri Konselor Multibudaya dan Praktik Konseling Multibudaya. UNNES: Seminar Nasional Konseling Berbasis Multikultural.

Setyaputri, N.Y. 2017. Karakter Ideal Konselor Multibudaya Berdasarkan Nilai Luhur Semar. Jurnal Kajian Bimbingan dan Konseling, Vol 2(2): 58-65.

Sue, D.W., Arredondo, P., \& McDavis, R.J. 1992. Multicultural Counseling Competencies and Standards: A Call to the Profession. Journal of Counseling \& Development, Vol 70: 477-486.

Yunita, I., \& Wirawan, A.R. 2017. Perancangan Media Board Game Menggunakan Pendekatan Edutainment untuk Meningkatkan Minat Belajar Dasar Akuntansi pada Sekolah Menengah Atas Jurusan Sosial. Jurnal AKUNTANSI DAN Teknologi Informasi (JATI), Vol 11:114.

Yusup, F. 2018. Uji Validitas dan reliabilitas Instrumen Penelitian kuantitatif. Tarbiyah: Jurnal IImiah Fakultas Tarbiyah Universitas Islam negeri Antasari, Vol 7, No 1: 17-23. (Online). https://jurnal.uinantasari.ac.id/index.php/itijk/article/view/2100 